\title{
3D Weld Pool Surface Geometry Measurement with Adaptive Passive Vision Images
}

\author{
A new software framework was developed to measure the key features related to \\ welding pool $3 D$ geometry based on the $2 D$ passive vision images
}

\author{
BY Z. CHEN, J. CHEN, AND Z. FENG
}

\begin{abstract}
Monitoring weld pool geometry without the appropriate auxiliary light source remains challenging due to the interference from the intense arc light. In this work, a new software framework was developed to measure the key features related to welding pool three-dimensional (3D) geometry based on the two-dimensional (2D) passive vision images. It was found that the interference of the arc light on the weld pool image can be effectively controlled by adjusting the camera exposure time based on the decision made from machine learning classifier. Weld pool width, trailing length, and surface height (SH) were calculated in real time, and the result agreed with the measurement of the weld bead geometry. The method presented here established the foundation for real-time penetration monitoring and control.
\end{abstract}

\section{KEYWORDS}

-Weld Pool • 3D Geometry • Adaptive Passive Vision

- Penetration

\section{Introduction}

Visual sensing of the weld pool is a central task to building an intelligent arc welding system, which imitates a human welder's behavior. However, it becomes a challenging task due to the intensive arc light during arc welding. Extended research has been conducted to measure the weld pool surface using visual sensing approaches (Refs. 1-3). The related work can be classified under two categories: active vision sensing and passive vision sensing.

The active vision system uses the auxiliary light source for illumination, and most of the arc light is suppressed through the filter. Zhang et al. (Ref. 4) developed an active vision system to obtain the weld pool image with laser light source. A real-time algorithm was developed to extract the weld pool edge from two-dimensional (2D) images. Since the intensity inside the weld pool area was relatively low compared with the unmelted area, the weld pool edge can be extracted with conventional image processing methods, such as edge detection and image thresholding. However, reflection from the laser light may randomly appear inside the weld pool area, which may affect the weld pool segmentation.

The passive vision system uses the arc light as the major light source; thus, it is simple in the experiment setup compared with the active vision systems. The arc light was partially suppressed, and the weld pool edge can be visualized with appropriate exposure time. Conventional image processing algorithms were applied to extract the weld pool edge during pulsed gas tungsten arc welding (GTAW-P) for bead-on-plate and butt joint welds (Refs. 5-10).

Three-dimensional (3D) geometry of the weld pool surface provides more information for penetration detection than 2D (Ref. 3). In Ref. 11, an active vision 3D weld pool sensing system was developed by Zhang's group. The laser structure light was projected on the surface of the weld pool, and the reflected pattern was obtained on a project plane. The 3D weld pool surface was reconstructed based on the distortion of the reflected pattern (Ref. 12). The follow-up work done by Liu et al. correlated the measured 3D weld pool surface geometry to weld joint penetration as well as human welder operations (Refs. 13-15).

Zhao et al. introduced the shape from shaping (SFS) method to recover the 3D information from the single 2D passive vision image (Ref. 16). However, the accuracy of surface height calculated may be affected by the variation of the arc light source. In our previous research (Ref. 17), a new method based on law of reflection was proposed to calculate the surface height of the weld pool from the reversed electrode image (REI), a virtual image electrode tip produced by weld pool surface reflection. Since the REI is obtained in a short exposure time, it is less affected by the variation of arc light.

In this paper, we aimed to develop a simple passive vision sensing system to measure three key features of the 3D weld pool surface, including weld pool width, trailing length, and surface height from 2D images. The machine learning method was integrated into the software to control the camera exposure time. The arc light interference for the passive vision system was effectively reduced, which ensured the quality of the weld images. The algorithm was verified in the 


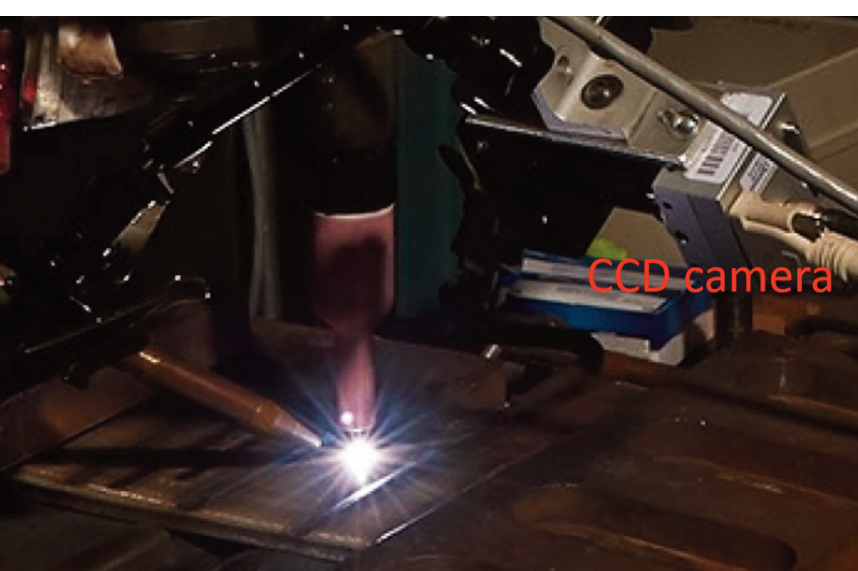

Fig. 1-Passive vision weld pool image acquisition system.

welding experiments with a current between 50 and $150 \mathrm{~A}$. The key features of the 3D weld pool surface geometry were measured with sufficient accuracy and can be used as the major variables to indicate weld penetration.

\section{Experiment Setup}

\section{Principle of 3D Weld Pool Geometry Measurement}

The experiment setup is shown in Fig. 1. The welding torch was set perpendicular to the workpiece. The hall-effect current sensor and arc voltage control unit were integrated with the welding system to measure the welding current and voltage in real time. A high-speed camera was mounted on the right side of the moving torch. During the arc welding process, the torch traveled from right toward left in the figure. The filler wire can be added from the left side of the torch. A band pass filter was placed in front of the charge-coupled device (CCD) camera to reduce the interference of arc light.

\section{Definition of Variables}

An illustration of the variables related to 3D weld pool geometry for bead-on-plate welding is shown in Fig. 2. In Fig. 2A, the topside view contains 2D information of the weld pool top surface. Assuming a teardrop-shaped weld pool surface is formulated for the bead-on-plate weld, point $C$ is the center of the weld pool, which is underneath the tungsten electrode. Weld pool front length $\left(L_{f}\right)$ is between point $O$ and $C$. Since point $O$ was blocked by the arc light, the front length cannot be calculated with this configuration. In this paper, the three key features to describe weld pool surface, including weld pool topside width $\left(W_{t}\right)$, weld pool trailing length $\left(L_{t}\right)$, and surface height $(\mathrm{SH})$, can be calculated from the 2D image. $L_{t}$ is defined as the distance between point $C$ and $D$, which is an important variable related to weld penetration. Figure $2 \mathrm{~B}$ describes the cross-section view of the weld pool at complete joint penetration condition. The surface height is defined as the distance between the base metal surface and the vertex of the weld pool surface. SH is less than zero as a concave surface is formulated. Weld backside width $\left(W_{b}\right)$ and root reinforcement on the

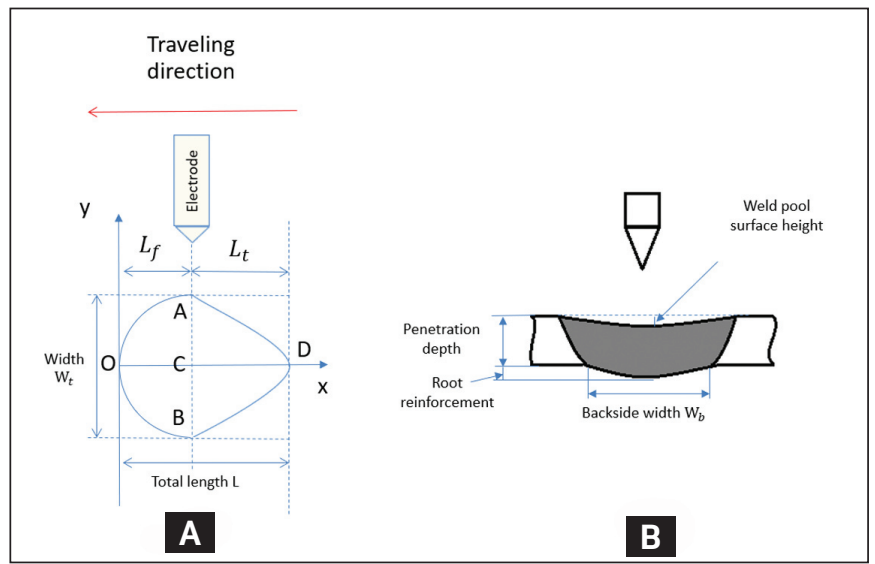

Fig. 2 - Definition of variables: A - Topside view of the weld pool top surface; $B$ - the cross-section view of the weld pool.

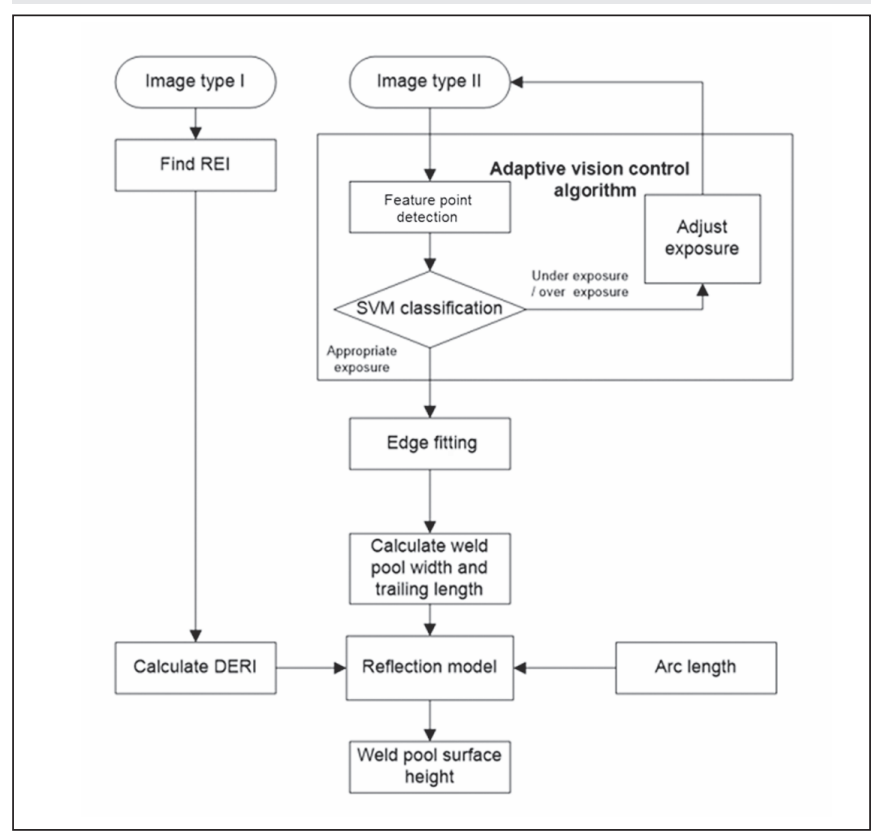

Fig. 3 - Framework of 3D weld pool geometry calculation.

backside of the workpiece are the direct variables to describe weld penetration.

\section{Software Framework}

The flow chart to calculate the 3D weld pool geometry is shown in Fig. 3. Two types of passive vision images were obtained alternatively through a CCD camera. As shown in Fig. $4 \mathrm{~A}$, image type I was obtained at $10 \mu$ s exposure time. The arc light was almost suppressed. Only a tungsten electrode tip and the REI were visible in the image. The REI is a virtual image of the electrode tip due to the mirror reflection of the weld pool surface. DERI is the distance between the REI and the electrode tip, which can be calculated using the algorithm developed in a previous research (Ref. 17).

Image type II was obtained at appropriate exposure times, as shown in Fig. 4B. Although the center of the weld pool was blocked by the arc, the weld pool boundary is clearly visible. Image type II was used to extract the 2D weld pool boundary. 

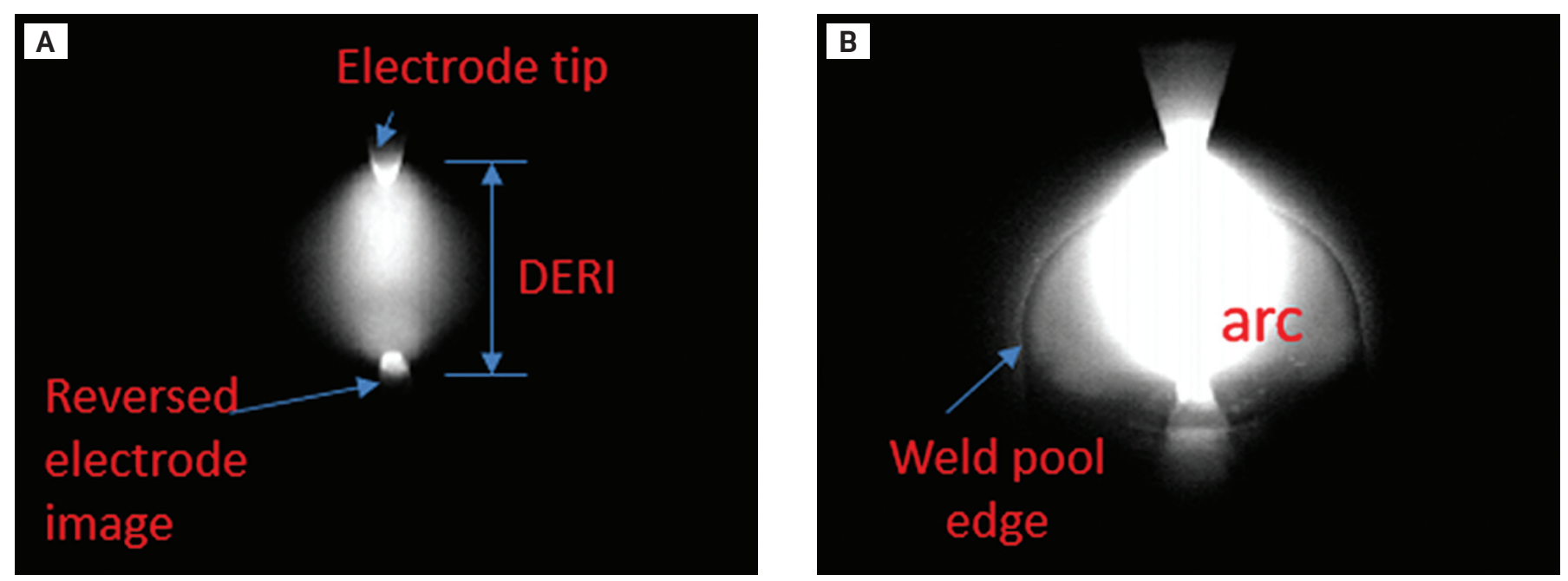

Fig. 4 - Passive vision weld pool image: A - Image type l; B - image type II.

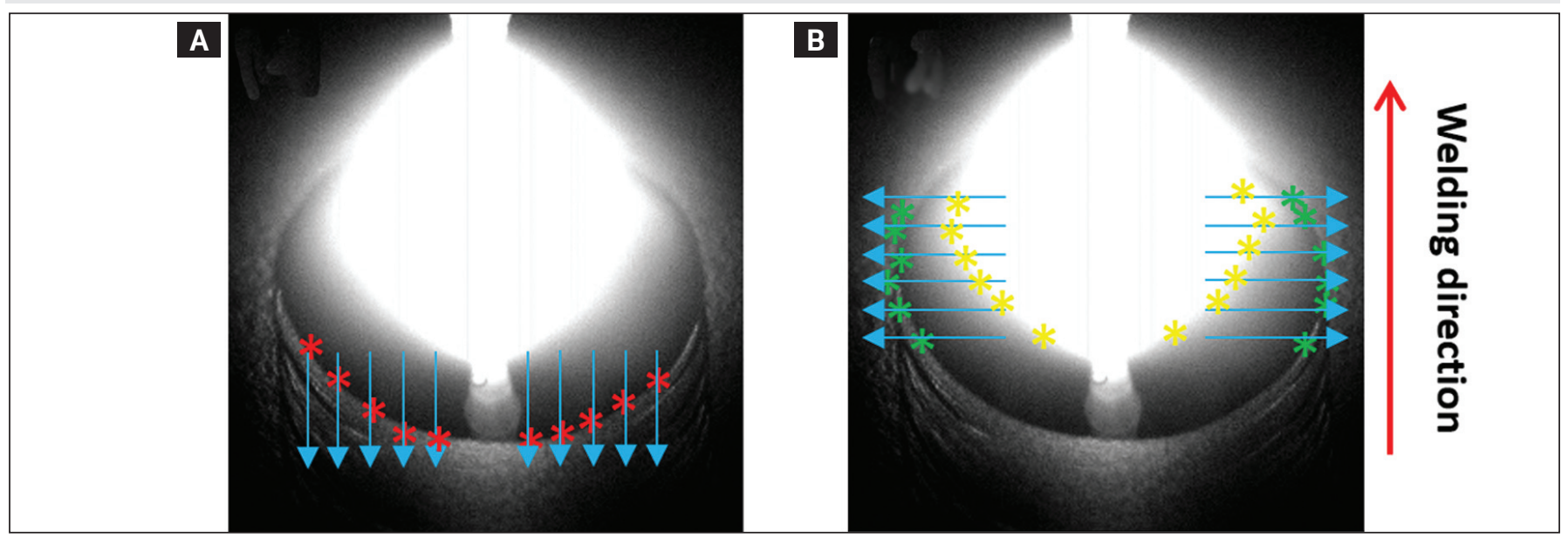

Fig. 5 - Searching feature points on passive vision image: A - Vertical searching; B - horizontal direction.

The appropriate exposure time can be determined through the adaptive exposure control algorithm, which includes four parts: edge detection, feature generation, classification, and exposure time adjustment. As shown in Fig. 5, we search for the feature points on the greyscale image along the scanning lines in the vertical and horizontal direction. The coordinate of each feature point was determined based on the intensity variation along one scanning line.

\section{Table 1 - Extracted Features from Detected Landmarks}

\section{No. Features Description}

\section{Average intensity of the image}

2 Number of process relevant pixels on left edge

3 Number of process relevant pixels on right edge

4 Dl: width of the saturated area

$5 \quad$ D2: maximum distance between two fitted curves

$6 \quad$ SSR of the curve fitting on left edge

7 SSR of the curve fitting on right edge

8 STD of green PRP's on left edge in $y$ direction

9 STD of green PRP's on right edge in $y$ direction
There are three kinds of feature points generated from the weld pool images. The red feature points indicated the maximum intensity gradient along the vertical scanning line in Fig. 5A. In Fig. 5B, the green feature points indicated the maximum intensity gradient along the horizontal scanning line, and the yellow feature points indicated the edge of saturated arc light area.

The detected feature points played an important role for image processing. First, the features related to the camera exposure condition were extracted based on the distribution of feature points. Second, the green feature points were used to determine the weld pool edge for the weld pool image obtained at appropriate exposure conditions.

The features related to camera exposure conditions were generated based on the distribution of the detected feature points. A classification model based on the support vector machine was trained to determine the exposure condition of the weld pool image. If the weld pool image was under- or overexposed, the camera exposure time would be regulated until the appropriately exposed image was obtained. Once the weld pool image is appropriately exposed, the feature points can be found on the edge of the weld pool. The weld pool edge was fitted based on the detected feature points. 

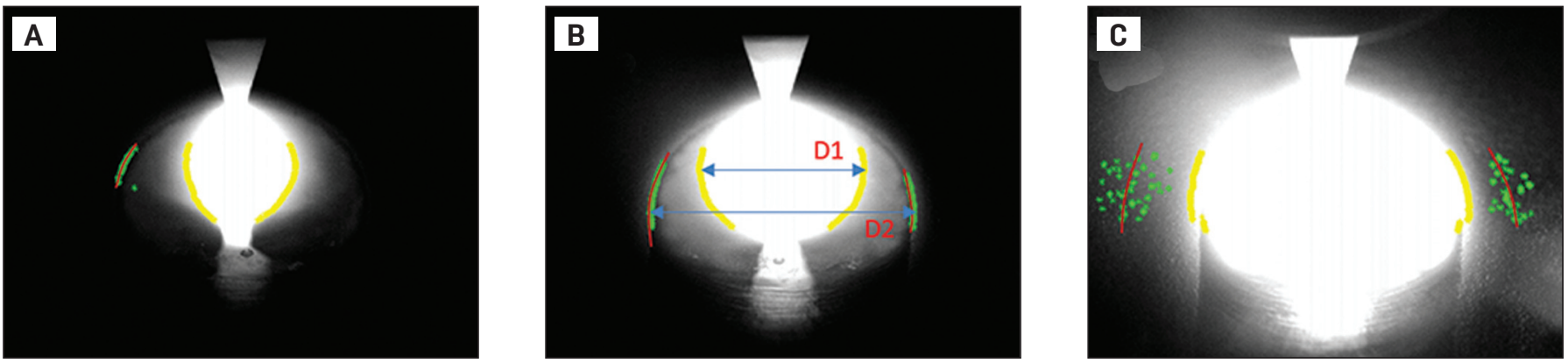

Fig. 6 - Feature points detection under three exposure conditions: A - Underexposed image; B - appropriate exposed image; C overexposed image.
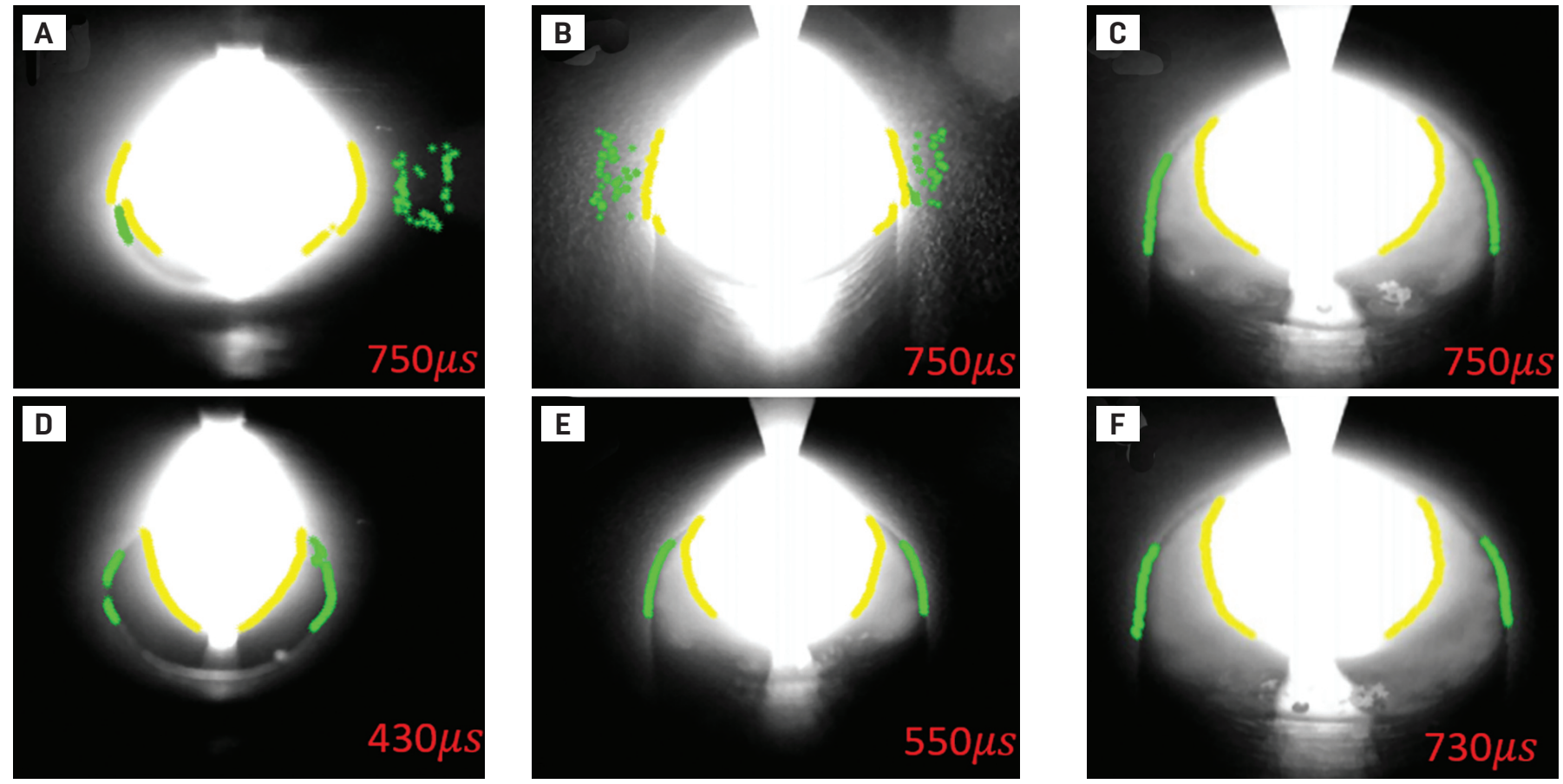

Fig. 7-A-C - Feature points detection on the weld pool image obtained with constant exposure time at $750 \mu s ; D-F-$ feature points detection on the weld pool image obtained with adaptive controlled exposure time.

Then, $W_{t}$ and $L_{t}$ can be calculated with the detected weld pool edges.

Based on our previous research (Ref. 17), the DERI is related to the curvature of the weld pool surface and the arc length. After calibration, the arc length $(D O)$ can be determined from the arc voltage signal using the voltage sensor. The SH was calculated from D0, DERI, and weld pool width $\left(W_{t}\right)$ based on the following equation:

$$
\frac{-4^{*} S H}{\left(W_{t} / 2\right)^{2}+S H^{2}}=\frac{1}{D 0}+\frac{1}{D 0-D E R I}
$$

\section{Adaptive Exposure Control Algorithm}

\section{Image Exposure Condition Classification}

The distribution of feature points can reflect the exposure condition of weld pool images. The detected feature points on the horizontal direction for the three exposure conditions were shown in Fig. 6.

Figure $6 \mathrm{~A}$ describes the detected feature points for the underexposed image. The green feature points on the weld pool side edge can hardly be detected correctly due to the insufficient exposure. In the appropriate exposure condition shown in Fig. 6B, the green feature points were detected on the weld pool side edge. For the overexposure image shown in Fig. 6C, the saturated arc light covered the side edge. The green feature points were randomly distributed outside the weld pool area. Hence, only if the weld pool image was obtained under appropriate exposure time, the green feature points can be found on the edge of the weld pool.

As shown in Table 1, nine features were extracted for the detected feature points and the original image. Polynomial curve fitting was applied twice on the green feature points as reference. Features 6 and 7 were the sum of squared errors (SSR) of the curve fitting. Features 8 and 9 were the standard deviation of the green feature points location in the y direction.

The support vector machine (SVM) classification model 


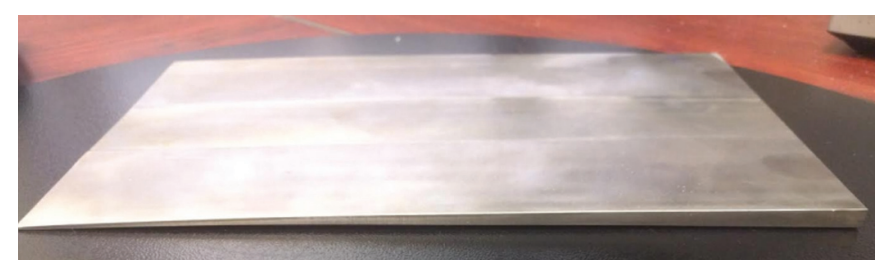

Fig. 8-Wedge-shaped SS304 workpiece.

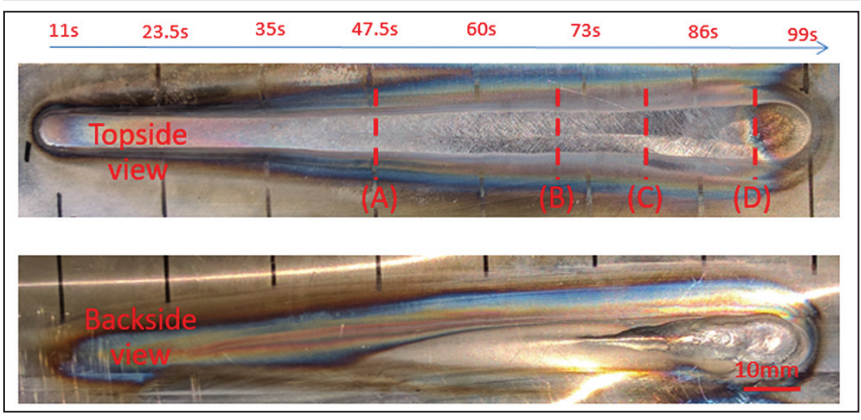

Fig. 9-Front and backside view of the weld bead.

was trained to determine the exposure conditions into underexposed, appropriate exposed, and overexposed conditions based on the nine extracted features. In the linear SVM classification problem, the hyper plane was found by solving an optimization problem that separates the data with maximal margin (Ref. 18). The classification model was trained with 120 weld pool images with 5 -folds cross validation, which includes 35 underexposed images, 36 overexposed images, and 49 appropriate exposed images. The SVM provides a good generalization for this classification problem. The average accuracy of the classification model was $98.6 \%$.

\section{Validation of Adaptive Exposure Control}

Two bead-on-plate autogenous welds were performed on the 6-mm-thick SS304 plate. The welding current changed between 100, 120, and 150 A during one weld. The welding voltage was controlled at $11 \mathrm{~V}$ through the arc voltage control system. Welding speed was $2 \mathrm{~mm} / \mathrm{s}$. Argon shielding gas flow rate was set at $20 \mathrm{ft}^{3} / \mathrm{h}$. As shown in Fig. 7A-C, the weld pool images of the first weld were obtained under constant exposure time at $750 \mu \mathrm{s}$. However, the arc light overwhelmed the weld pool area when the welding current was 100 and $120 \mathrm{~A}$. The weld pool boundary can be observed as the current went up to $150 \mathrm{~A}$. Thus, a constant camera exposure time may not be able to obtain high-quality weld pool images when the welding current is changed during the weld.

A second weld was performed with the same welding parameters as the first one. However, the adaptive exposure control algorithm was applied during the weld. The weld pool images and detected feature points are shown in Fig. 7D-F. The exposure time was increased with the increase of the weld pool area because more illumination is required to extract the whole weld pool boundary. The green marks were detected on the side edge for all three currents. Hence, the weld pool images under appropriate exposure conditions were obtained using the proposed algorithm. The weld pool boundary can be further extracted based on the green feature points.
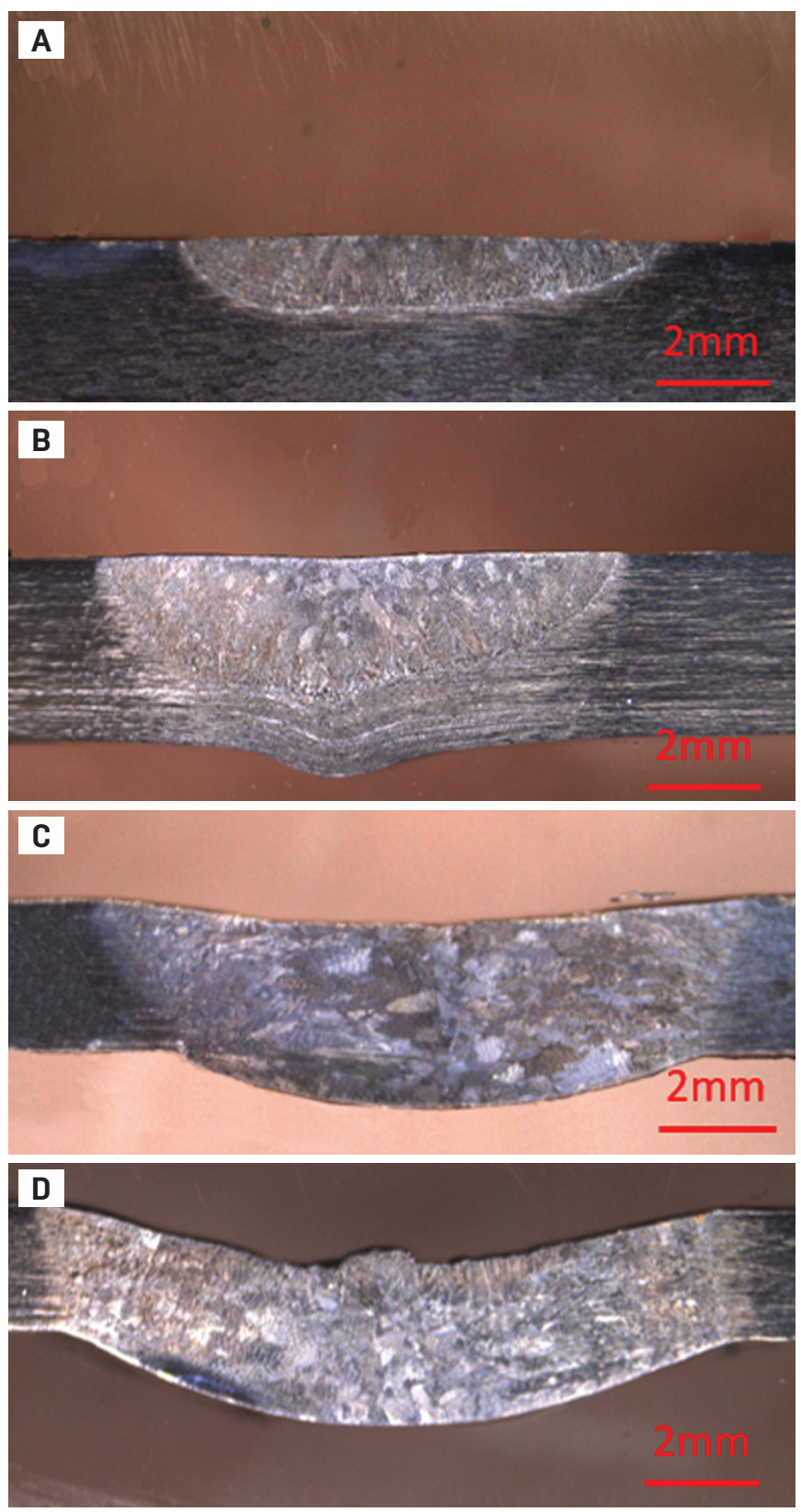

Fig. 10 - Cross section view of the weld bead: $A$ - Incomplete joint penetration at $50 \mathrm{~s} ; \mathrm{B}$ - incomplete joint penetration at $70 \mathrm{~s} ; \mathrm{C}$ - Complete joint penetration at $80 \mathrm{~s} ; \mathrm{D}-$ overpenetration at $90 \mathrm{~s}$.

\section{Results of 3D Weld Pool Geometry Measurement}

The experiment of measuring the weld pool geometry was conducted on a wedge-shaped SS304 plate, as shown in Fig. 8. The weld current remained constant at 120 A. Welding speed was $2 \mathrm{~mm} / \mathrm{s}$. The thickness of the plate gradually reduced from 6 to $2 \mathrm{~mm}$.

The topside and back view of the weld are shown in Fig. 9. The blue arrow bar indicated the timeline of the welding process. The weld was started from the 6 -mm-thick end travel to the 2-mm-thick end. The topside width of the weld 

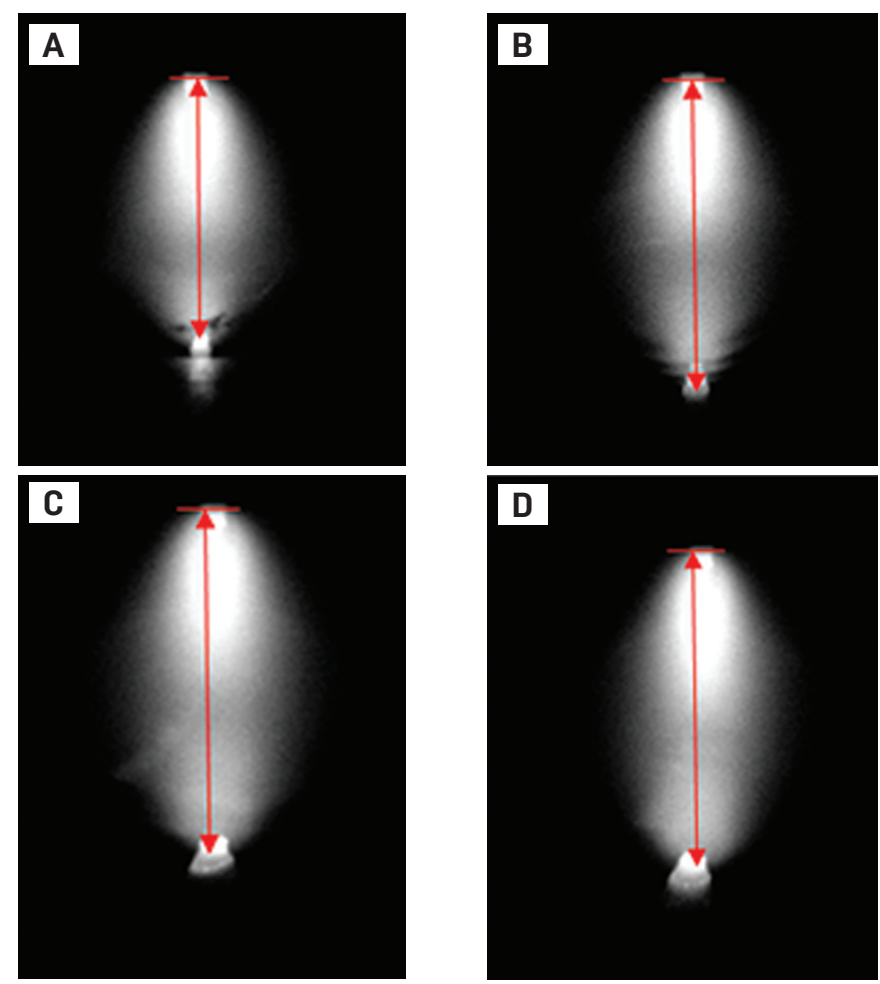

Fig. 11 - Comparison of DERI from image type I: A - Image obtained at $50 \mathrm{~s} ; B-70 \mathrm{~s} ; C-80 \mathrm{~s} ; D-90 \mathrm{~s}$.

bead was increased by the decrease of workpiece thickness. The weld pool gradually penetrated the plate as the thickness reduced, which can be seen from the backside.

In Fig. 10, the cross-section views of the weld bead were collected at four locations (marked in Fig. 9) with different penetration conditions: incomplete, complete, and over penetration. Figure 10A, B shows an incomplete weld where the fusion did not go through the whole material. The face reinforcement of the weld bead is close to zero. Figure $10 \mathrm{C}$ shows a completely penetrated weld as the fusion extends through the thickness of the material, and a concave weld bead surface was formulated. The concavity of the weld bead top surface was increased in Fig. 10D, as the penetration depth increased. This weld can be considered as over penetration since the root reinforcement exceeded the $1 / 4$ of material thickness based on the ASME Boiler and Pressure Vessel Code (Ref. 19).

The corresponded REI images obtained with $10 \mu \mathrm{s}$ is shown in Fig. 11. The image was obtained at 50, 70, 80, and $90 \mathrm{~s}$ after the weld started. As the penetration increased, DERI was extended, and the area of REI increased, resulting from the concavity of the weld pool surface. The concave weld pool surface serves as a concave mirror to generate an amplified REI. The DERI was increased with the increase of weld pool surface concavity.

The corresponded weld pool images obtained at 50, 70, 80, and $90 \mathrm{~s}$ are shown in Fig. 12. The weld pool can be visualized with appropriate camera exposure time. The 2D weld pool boundary was fitted using polynomial regression with the detected feature points. An ellipsoid-shaped weld pool can be observed from the rear camera as shown in Fig. 12A, $B$. The weld pool area was increased with the increase of weld penetration. A teardrop-shaped weld pool was formu-
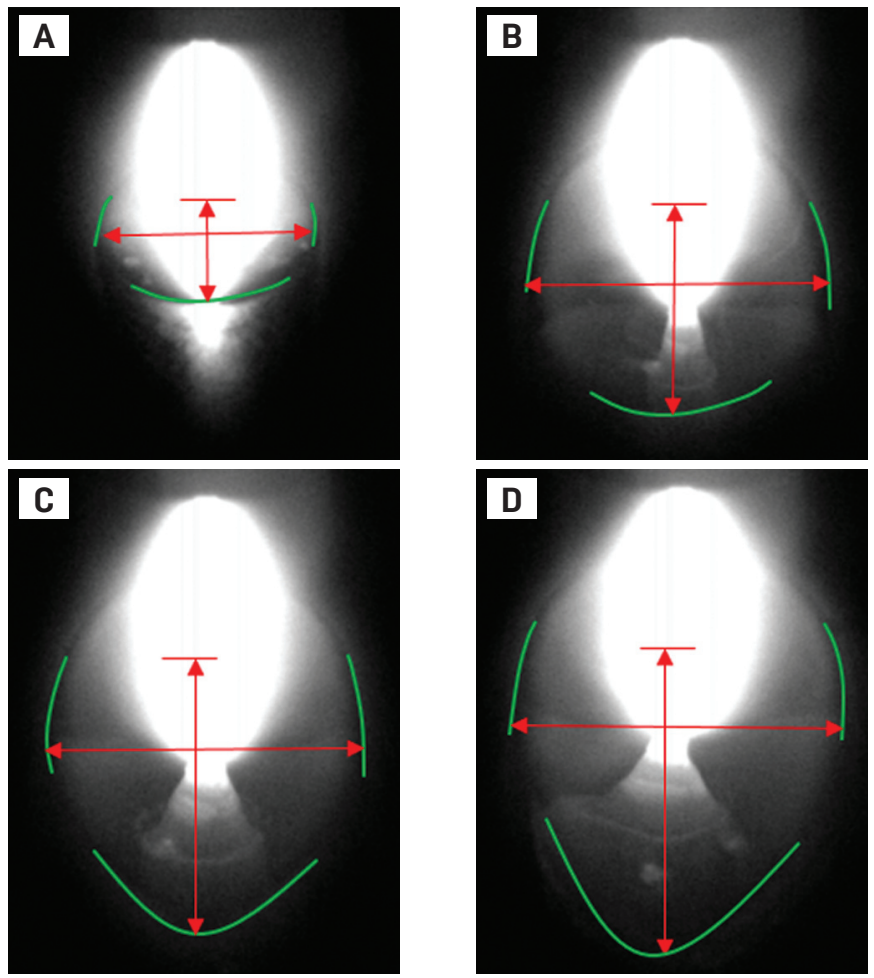

Fig. 12 - Weld pool edge detection from image type II. Images obtained at $50 \mathrm{~s} ; \mathrm{B}-70 \mathrm{~s} ; \mathrm{C}-80 \mathrm{~s} ; \mathrm{D}-90 \mathrm{~s}$.

lated at complete joint penetration in Fig. 12C and D.

The distortion of the workpiece was more likely to be created at the end of the weld as the workpiece thickness is reduced. Due to the workpiece distortion, the unsymmetrical weld pool shape in Fig. 12D was observed. Thus, a good clamping is required to alleviate the effect of distortion.

The weld pool width can be calculated in real time with the proposed algorithm. The algorithm was implemented using MATLAB. The image processing time to extract REI took less than $10 \mathrm{~ms}$ per frame, and time consumption for weld pool edge detection was between 20 and 50 ms. Overall, time consumption in each period of measurement was below $100 \mathrm{~ms}$, which is sufficient to be applied in real time.

Figure 13 shows the calculated result of the weld pool width $W_{t}$ and trailing length $L_{t}$ based on the weld pool edge detection algorithm. The green dots indicate bead width measured after welding. The calculated weld pool width is coherent with the bead width on the topside of the workpiece. The mean square error (MSE) between the calculated weld pool width and weld bead width is $0.12 \mathrm{~mm}$. From the curve in Fig. 13, the increasing rate of $W_{\mathrm{t}}$ was slowed down as the weld closed to complete joint penetration. The weld pool trailing length continuously increased and exceeded the width of weld pool as the complete joint penetration occurred. Meanwhile, the weld pool area changed from an ellipsoid shape to a long teardrop shape with a small rear angle.

In Fig. 14, the weld pool surface height was calculated using the REI method. The red dot around the curve was the face reinforcement of the weld bead. The calculated SH was close to the measurement of face reinforcement. The standard deviation between the calculated $\mathrm{SH}$ and weld bead face reinforcement was 0.25 . The decreasing rate significant- 


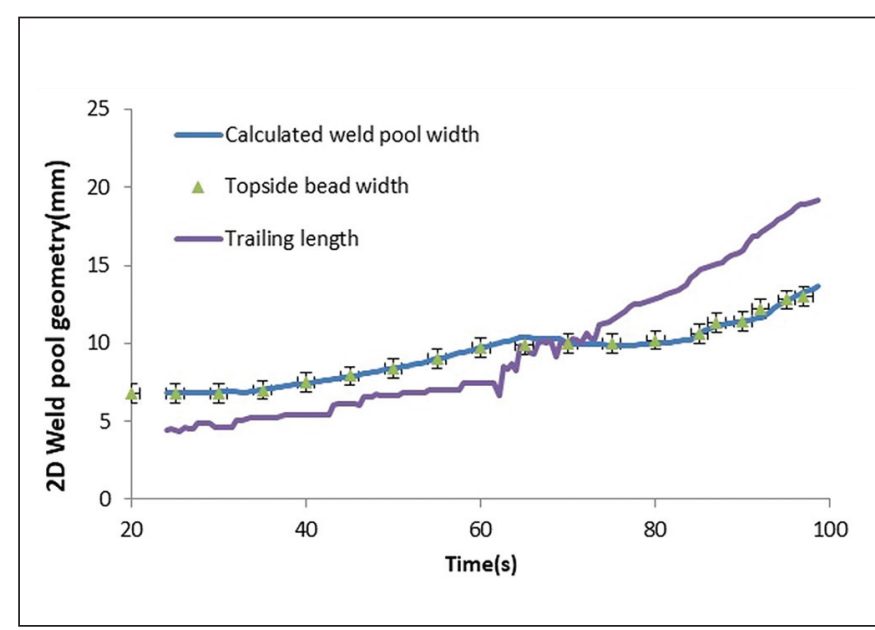

Fig. $13-2 D$ geometry measurement of the topside weld pool.

ly increased as the weld became over penetrated. Surface tension becomes the major force to support the weld pool from melting through. The concavity of the weld pool top surface increased due to gravity.

\section{Conclusion}

In this paper, the new image processing framework based on an adaptive exposure control algorithm was developed to obtain three key features of 3D weld pool surface geometry. The conclusions can be drawn as follows:

1) The camera exposure time significantly affected the accuracy of edge detection on weld pool images.

2) The SVM classification model can determine the exposure condition of the weld pool image with sufficient accuracy. The camera exposure time was adaptively adjusted to obtain the weld pool image under appropriate exposure condition. The interference from the arc light was effectively controlled.

3) The calculated weld pool width and surface height were close to the actual weld bead size measured after welding.

4) The three key features $W_{t}, L_{t}$, and SH were closely related to the weld penetration. $L_{t}$ value exceeded $W_{t}$ as complete joint penetration started. $\mathrm{SH}$ was below zero at complete joint penetration and significantly reduced as the overpenetration started.

\section{Acknowledgments}

This research was sponsored by the U.S. Department of Energy, Office of Nuclear Energy, for Nuclear Energy Enabling Technologies Crosscutting Technology Development Effort, under a prime contract with Oak Ridge National Laboratory (ORNL). ORNL is managed by UT-Battelle LLC for the U.S. Department of Energy under Contract DE-AC05-00OR22725.

\section{References}

1. Chen, S. B., et al. 2004. Computer vision sensing and intelligent control of welding pool dynamics. Robotic Welding, Intelligence and Automation. Springer, Berlin, Heidelberg.

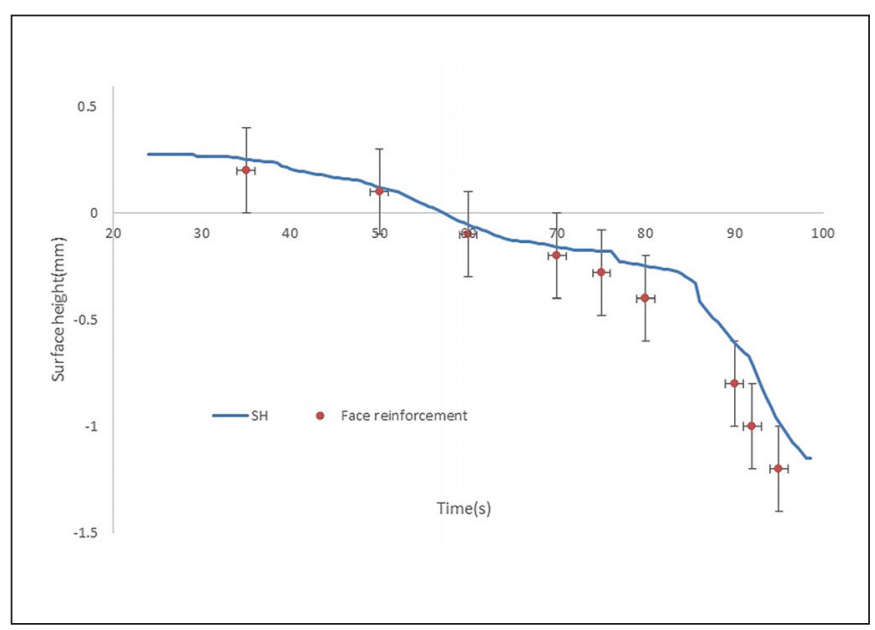

Fig. 14 - Measurement of the weld pool surface height.

pp. 25-55.

2. Chen, S. B., et al. 2003. Extraction of three-dimensional parameters for weld pool surface in pulsed GTAW with wire filler. Journal of Manufacturing Science and Engineering 125(3): 493-503.

3. Wang, X. 2014. Three-dimensional vision-based sensing of GTAW: A review. The International Journal of Advanced Manufacturing Technology 72(1-4): 333-345.

4. Kovacevic, R., Zhang, Y. M., and Li, L. 1996. Monitoring of weld joint penetrations based on weld pool geometrical appearance. Welding Journal 75(10): 317-329.

5. Wu, J., and Chen, S. B. 2007. Software system designs of real-time image processing of weld pool dynamic characteristics. Editors T.-J. Tarn, S.-B. Chen, and C. Zhou. Robotic Welding, Intelligence and Automation. Springer, Berlin, Heidelberg. pp. 303-309.

6. Li, W., Ji, Y., Wu, J., and Wang, J. 2015. A modified welding image feature extraction algorithm for rotating arc narrow gap MAG welding. Industrial Robot: An International Journal 42(3): 222-227.

7. Li, W., et al. 2015. Groove sidewall penetration modeling for rotating arc narrow gap MAG welding. The International Journal of Advanced Manufacturing Technology 78(1-4): 573-581.

8. Shen, H.-Y., et al. 2008. Arc welding robot system with seam tracking and weld pool control based on passive vision. The International Journal of Advanced Manufacturing Technology 39(7-8): 669-678.

9. Li, W., Wu, J., Hu, T., and Yang, F. 2015. Rough set based modeling for welding groove bottom state in narrow gap MAG welding. Industrial Robot: An International Journal 42(2): 110-116.

10. Li, W.-H., et al. 2015. Modeling welding deviation of rotating arc NGW based on support vector machine. Editors T.-J. Tarn, S.-B. Chen, and X.-Q. Chen. Robotic Welding, Intelligence and Automation: RWIA'2014. Springer International Publishing: Cham. p. 459-468.

11. Song, H. S., and Zhang, Y. M. 2008. Measurement and analysis of three-dimensional specular gas tungsten arc weld pool surface. Welding Journal 87(4): 85-s to 95-s.

12. Zhang, W., et al. 2012. Characterization of threedimensional weld pool surface in GTAW. Welding Journal 


\section{WELDING RESEARCH}

91(7): 195-s to 203-s.

13. Liu, Y.-K., and Zhang, Y.-M. 2013. Control of 3D weld pool surface. Control Engineering Practice 21(11): 1469-1480.

14. Liu, Y.-K., and Zhang, Y.-M. 2017. Fusing machine algorithm with welder intelligence for adaptive welding robots. Journal of Manufacturing Processes 27: 18-25.

15. Liu, Y.-K., and Zhang, Y.-M. 2014. Model-based predictive control of weld penetration in gas tungsten arc welding. IEEE Transactions on Control Systems Technology 22(3): 955-966.

16. Zhao, D. B., et al. 2003. Extraction of three-dimensional parameters for weld pool surface in pulsed GTAW with wire filler. Journal of Manufacturing Science and Engineering 125(3): 493-503.
17. Chen, Z., Chen, J., and Feng, Z. 2017. Monitoring weld pool surface and penetration using reversed electrode images. Welding Journal 96(10): 367-s to 375-s.

18. Scholkopf, B., and Smola, A. 2002. Learning with Kernels. Cambridge, Mass.: MIT Press.

19. American Society of Mechanical Engineers. 2004. Boiler and Pressure Vessel Code, Section VIII, Division 1. NG3000 .

ZONGYAO CHEN (fengz@ornl.gov) is with Air Liquide, Newark, Del. JAN CHEN and ZHILI FENG are with Oak Ridge National Laboratory, Oak Ridge, Tenn.

\section{Welding Journal Now Publishing Direct Object Identifier (DOI) Numbers}

Dear members of the welding research community,

Note that in each issue of the Welding Journal Research Supplement, we are including Direct Object Identifier (DOI) numbers with each of the papers published in print and online. A direct object identifier is a unique alphanumeric string assigned by a registration agency (we are using Crossref.org) to identify content and provide a persistent link to its location on the Internet. Our decision to begin assigning a DOl for each paper comes directly from a request by the research community.

As part of our obligation to Crossref.org, we are asked to provide DOI numbers, when available, in the references section of papers. So, if you have submitted a paper to the Welding Journal or are planning on submitting a paper, we ask that you update your references to include DOI numbers whenever possible.

Thank you.

Mary Ruth Johnsen,

Publisher, Welding Journal 